\title{
MULTIJURISDICTIONAL FIRMS AND GOVERNMENTS' STRATEGIES UNDER AlternATIVE TAX DESIGNS
}

\author{
MARCEL GÉRARD
}

CESIFO WORKING PAPER No. 1527

CATEgOry 1: Public FinANCE

August 2005

Presented at CESifo AREa CONFERENCE ON

Public SECTOR ECONOMICS, APRIL 2005

An electronic version of the paper may be downloaded

- from the SSRN website:

www.SSRN.com

- from the CESifo website:

www.CESifo-group.de 


\title{
MULTIJURISDICTIONAL FIRMS AND GOVERNMENTS' STRATEGIES UNDER Alternative TAX DeSIGNS
}

\begin{abstract}
Conducted in a framework which embodies tax-shifting opportunities, risk of losses and possibility of interjurisdictional loss-offset, this paper investigates a reform of multijurisdictional enterprises taxation, a move from Separate Accounting to Formulary Apportionment. Findings are summarised in a series of propositions on the strategic behaviour of enterprises and authorities. Under Separate Accounting, tax-shifting opportunities reduce investment in the lower-taxing jurisdiction, tax sensitivity of investment and tax competition. Moving to Formulary Apportionment eliminates such opportunities, pushing the economy in the opposite direction. Permitting the firm to compensate losses among affiliates allows it to benefit from a tax-shifting and insurance device.
\end{abstract}

JEL Code: H32, H73, H87.

Keywords: multijurisdictional enterprise, separate accounting, formulary apportionment, cross-border loss offset.

\author{
Marcel Gérard \\ Catholic University of Mons \\ Chaussée de Binche 151 \\ 7000 Mons \\ Belgium \\ gerard@fucam.ac.be
}

This paper has been undertaken when I was visiting the Office of Tax Policy Research of the University of Michigan in November 2004. I want to thank James Hines and Joel Slemrod for their hospitality. Successive drafts of this paper were presented at a Cerge-EI-Cepii Conference in Prague in December 2004, then at Suite seminar in Lille, Cesifo Area in Public Economics meeting in Munich, CEPEG meeting in Hamilton and the APET Conference in Marseille, all in 2005. Comments from Agnes Benassy, Clemens Fuest, Stefan Homburg, Fernando Ruiz and Michael Smart are gratefully acknowledged. The paper expands previous work with Joann Weiner, see Gerard and Weiner (2003, 2005). 


\section{Introduction}

Twenty years ago, Gordon and Wilson published a seminal paper on Formulary Apportionment (hereafter referred to as FA) in Econometrica (Gordon-Wilson, 1986). They suggested in particular that this way of distributing the tax base of a multijurisdictional company among the jurisdictions in which it operates, in order to be taxed, could increase tax competition. That paper was primarily motivated by the adoption of such a system by states in the US and it gave rise in turn to a large volume of economic literature, mainly in North America (see e.g. Mintz and Smart, 2004).

The European Union is currently discussing the replacement of the present system, based on OECD model tax treaties (hereafter referred to as SA for Separate Accounting) with such a system (EU Commission, 2001). As a consequence, we observe a renewed interest in research into the pros and cons of taxing multijurisdictional firms using an FA system (see e.g. Sorensen, 2004). Moreover, the discussion is being conducted within the context of strong tax competition between jurisdictions. Very recently, the opinion of the advocate general to the European Court of Justice in the Mark and Spencer vs David Halsey (HM Inspector of Taxes) case has brought again to the forefront the issue of group relief for cross border losses; such a relief is included in the EU move to FA proposal but it can also be set up separately as a desirable targeted measure, as recognised by the EU Commission itself and strongly supported by Unice, the EU wide association of employers (Unice, 2000).

Compared to existing literature - see the references at the end of the paper - this contribution attempts to reshape the discussion on the respective merits of SA and FA in a broader context, defined in terms of strategic opportunities for multijurisdictional enterprises (denoted MJE in the rest of this paper), and characterisations of the economic environment. We introduce devices for tax-shifting, such as the opportunities presented by transfer pricing strategies, and the risk of incurring losses. In this way, we encompass a number of areas which are relevant for both a theoretical and a policy-oriented debate.

For the reader who is not familiar with tax institutions, let us note that under SA, every affiliate of an MJE is taxed in the jurisdiction where it operates and possible losses are only deductible against each affiliate's own future profits according to a carry-forward process. In 
comparison, under FA, the profits of the various affiliates of an MJE, operating within a given perimeter in terms of geography and ownership, are first consolidated. They are then redistributed among the jurisdictions of operation according to a given formula - such as the distribution of property, of sales or of labour costs, or some combination of these factors - in order to allow each government to tax its own part of the consolidated profit at its own corporate income tax rate. Hence FA implies interjurisdictional loss offset within the consolidation perimeter. However, cross-border loss offset can also be introduced within an SA framework, without moving to FA.

In the rest of this paper, we discuss these two alternative tax designs and investigate their effects on the strategic behaviour of both MJEs and government authorities. We summarise our findings in a series of propositions, which are supported by our model.

In section 2 of this paper, we investigate a simple, benchmark, situation with only two jurisdictions involved and no room for strategic tax shifting opportunities for the MJE. We start considering the MJE operates under SA, then we investigate a move to FA and its consequences for both the MJE and the jurisdictions authorities. We show in particular that , depending on the apportionment formula used, the move to FA can either keep unchanged or decrease tax competition.

Then, in section 3, next to the two active jurisdictions, we introduce a passive one - we define an active jurisdiction as one where the MJE has an active entity, as opposed to a jurisdiction where the firm has only a passive entity, not hosting a real investment - and we first show that, under SA, transfer pricing strategies and other tax-shifting opportunities globally reduce, at given tax rates, the fraction of investment in the lower-taxing active jurisdiction observed in the benchmark case. We also show that those devices reduce the sensitivity of the distribution of investment to tax changes and, pushing up tax rates at Nash equilibrium, the degree of interjurisdictional tax competition. However, moving to FA eliminates such opportunities and acts as an incentive to increase the fraction of investment in the lowertaxing active jurisdiction, the sensitivity of the distribution of investment to tax changes and the degree of interjurisdictional tax competition. As a consequence, the reform may boost tax competition, although the composition of the apportionment formula qualifies that result, making it unambiguous only when apportionment is solely function of the distribution of property (investment). Thereby we extend the Gordon-Wilson results into a broader context. 
On the other hand, we show in section 4 that permitting the MJE to compensate losses among its affiliates located in different jurisdictions allows it to use a tax-shifting and insurance device. Thus, under SA, the fraction of investment in the lower-taxing active jurisdiction is reduced, as are also the sensitivity of the distribution of investment to tax changes and the degree of interjurisdictional tax competition. In consequence, tax rates at Nash equilibrium go up and a move to FA may have the same consequences as some given above when tax shifting opportunities are removed. On this point, the paper follows Gerard and Weiner (2003, 2005).

Finally section 5 suggests conclusions, including some lessons for the conduct of fiscal policy and avenues for further and related research.

\section{A Simple Model of Investment Distribution and Tax Competition}

Let us start by focusing on a standard problem : the location choice of an investment by an MJE and the tax competition between two tax authorities in order to attract investment onto their territory.

A multijurisdictional firm has to distribute a given real unitary investment as a fraction $\alpha$ in jurisdiction $i$ and a fraction $1-\alpha$ in jurisdiction $j$. One unit of investment produces annually one unit of a consumption good. The MJE has to serve a fraction $q$ - not a decision variable for the MJE (suppose that the excess of sales over production in one jurisdiction is met by direct export from the other jurisdiction) - of that unit to market $i$ and a fraction 1- $q$ to the other market, in both cases at price $p$. There is no cost of operating production, so that the rates of profit are equal across jurisdictions; in other words, the two jurisdictions are identical except for demand for goods, and possibly for tax rates. The MJE wants to maximise its value $V$.

From a fiscal and legal point of view, consider that entity in jurisdiction $i$ is a parent company or entity while that in jurisdiction $j$ is either a branch or a subsidiary. If entity in $j$ is a branch it gets profits which, under separate accounting, SA, are taxed locally and then transferred to 
the parent entity where they are tax exempt. If entity in $j$ is a subsidiary its profits are, under the same tax design, also taxed locally; then they are repatriated to the parent company located in $i$, under the form of dividends which are not taxed in that country based on the exemption principle. As long as the tax rate in the parent jurisdiction does not exceed that in the one of the subsidiary, the application of the exemption principle encompasses that of the imputation mechanism. Under Formulary Apportionment, FA, a single consolidated tax base is computed for the two entity together, which is then distributed between the two jurisdictions in line with a predetermined formula, here a linear combination of the distribution of investments and sales, measured on a destination basis.

Throughout the paper we assume that there are no depreciation allowances and that the horizon of time can be approximated by infinity. In addition, in sections 2 and 3, there is no risk. Also, notice that in this model there is no room for change in the total amount of investment, but only for a substitution effect between alternative locations of fractions of a total amount of investment deemed to be equal to unity.

\subsection{Under Separate Accounting}

Let us first examine the behaviour of the MJE, then of the governments, assuming separate accounting, SA.

\section{a) The Multijurisdictional Firm}

Under that tax design, each affiliate is taxed on its own local profit by local authorities. Therefore the tax bases in $i$ and $j$ are

$$
B_{i}=\alpha \frac{p}{r}
$$

and

$$
B_{j}=(1-\alpha) \frac{p}{r}
$$

respectively. Denote by $\tau_{i}$ the corporate tax rate in jurisdiction $i$ and by $\tau_{j}$ its counterpart in $j$ and use a common discounting rate $r$, assuming the horizon of time approximated by infinity. We introduce a cost of departing from an initial distribution of investment 


$$
c(\alpha)=\frac{\gamma}{2}\left(\alpha-\alpha_{0}\right)^{2}
$$

Then the MJE maximises its value

$$
V=\frac{p}{r}-\tau_{i} B_{i}-\tau_{j} B_{j}-c(\alpha)
$$

with respect to $\alpha$. The f.o.c. of this problem is

$$
\frac{d V}{d \alpha}=\left(\tau_{j}-\tau_{i}\right) \frac{p}{r}-c_{\alpha}^{\prime}=\left(\tau_{j}-\tau_{i}\right) \frac{p}{r}-\gamma\left(\alpha-\alpha_{0}\right)=0
$$

and we obtain an equilibrium value for $\alpha$

$$
\alpha^{\circ}=\alpha_{0}+\frac{\tau_{j}-\tau_{i}}{\gamma} \frac{p}{r}
$$

where ${ }^{\circ}$ refers to this benchmark SA case. The sensitivity of that value to tax changes is given by the equations

$$
\frac{d \alpha}{d \tau_{i}}=-\frac{p}{\gamma r}<0, \frac{d \alpha}{d \tau_{j}}=\frac{p}{\gamma r}>0
$$

\section{b) The Governments}

The tax rates decided by the authorities of the respective jurisdictions are such that they maximise the social welfare function of each jurisdiction. Let us say, for $i$,

$$
W_{i}=s V+u T_{i}, T_{i}=\tau_{i} \alpha \frac{p}{r}
$$

where $s$ is the fraction of the MJE owned by taxpayers of $i$ and $u$ is the shadow price of public funds, $u>1$. Then the f.o.c. for government $i$ is

$$
\frac{d W_{i}}{d \tau_{i}}=(u-s) \alpha \frac{p}{r}+u \tau_{i} \frac{p}{r} \frac{d \alpha}{d \tau_{i}}=0
$$

so that

$$
\begin{aligned}
\tau_{i}^{\circ} & =-\frac{(u-s) \alpha}{u \frac{d \alpha}{d \tau_{i}}}=\frac{(u-s)}{u \frac{p}{\gamma r}}\left[\alpha_{0}+\frac{\tau_{j}-\tau_{i}}{\gamma} \frac{p}{r}\right] \\
& =\frac{u-s}{2 u-s}\left[\frac{\gamma r \alpha_{0}}{p}+\tau_{j}\right]
\end{aligned}
$$

an increasing function of the tax rate in the other jurisdiction. We further check the stability requirement that 


$$
1>\frac{d \tau_{i}}{d \tau_{j}}=\frac{u-s}{2 u-s}>0
$$

Similarly, in the other jurisdiction,

$$
\frac{d W_{j}}{d \tau_{j}}=[u-(1-s)](1-\alpha) \frac{p}{r}-u \tau_{j} \frac{p}{r} \frac{d \alpha}{d \tau_{j}}=0
$$

and

$$
\tau_{j}=\frac{u-(1-s)}{2 u-(1-s)}\left[\left(1-\alpha_{0}\right) \frac{\gamma r}{p}+\tau_{i}\right]
$$

Then, introducing the sole restriction that $s=.5$ we obtain the following benchmark values of the tax rates at Nash equilibrium

$$
\tau_{i}^{\circ}=k\left[\frac{\gamma r \alpha_{0}}{p}+\frac{u-s}{2 u-s} \frac{\gamma r\left(1-\alpha_{0}\right)}{p}\right]
$$

and

$$
\tau_{j}^{\circ}=k\left[\frac{\gamma r\left(1-\alpha_{0}\right)}{p}+\frac{u-s}{2 u-s} \frac{\gamma r \alpha_{0}}{p}\right]
$$

with

$$
k=\frac{\frac{u-s}{2 u-s}}{1-\left(\frac{u-s}{2 u-s}\right)^{2}}
$$

As a consequence, equation (5) becomes

$$
\alpha^{\circ}=\alpha_{0}+\frac{u-s}{3 u-2 s}\left(1-2 \alpha_{0}\right)
$$

and, especially, in a symmetric case

$$
\alpha^{\circ}=\alpha_{0}, \tau_{i}^{\circ}=\tau_{j}^{\circ}=\frac{u-s}{u} \frac{\gamma r \alpha_{0}}{p}, s=\alpha_{0}=.5
$$

The tax base in $i$, the tax revenue and the social welfare level in that jurisdiction are then respectively

$$
\begin{gathered}
B_{i}^{\circ}=\alpha \frac{p}{r}=\left[\alpha_{0}+k \frac{u}{2 u-s}\left(1-2 \alpha_{0}\right)\right] \frac{p}{r} \\
T_{i}^{\circ}=k\left[\frac{\gamma r \alpha_{0}}{p}+\frac{u-s}{2 u-s} \frac{\gamma r\left(1-\alpha_{0}\right)}{p}\right]\left[\alpha_{0}+k \frac{u}{2 u-s}\left(1-2 \alpha_{0}\right)\right] \frac{p}{r}
\end{gathered}
$$




$$
W_{i}^{\circ}=s\left(\frac{p}{r}-c\left(\alpha^{\circ}\right)-T_{j}^{\circ}\right)+(u-s) T_{i}^{\circ}
$$

and adaptation to the case of symmetric jurisdictions is straightforward.

\subsection{Under Formulary Apportionment}

Under Formulary Apportionment, FA, a common consolidated tax base, $B$, is first computed for the whole MJE. Then that consolidated tax base is apportioned in line with a predetermined formula. Suppose that the formula is a linear combination of two criteria, the distribution of property (investment) on the one hand, that of sales, computed on a destination basis, on the other hand. That means a variable which is under the control of the MJE property, since the MJE decides on the distribution of its investment - and another one which is not under such control - sales. Actually, that distinction is a simple way to introduce variability in the mobility of - and the elasticity to - the tax base under FA. Notice that if, for sales, we adopt the alternative principle, that of origin, using sales is equivalent to using property in this model. Formally,

$$
B_{i}=[\lambda \alpha+(1-\lambda) q] B
$$

and

$$
B_{j}=[\lambda(1-\alpha)+(1-\lambda)(1-q)] B
$$

with

$$
B=\frac{p}{r}
$$

\section{a) The Multijurisdictional Firm}

The program of the MJE still consists in maximising equation (4) with however the tax bases redefined using equations (13) and (14). It turns out that

$$
\alpha^{F A}=\alpha_{0}+\frac{\tau_{j}-\tau_{i}}{\gamma} \lambda \frac{p}{r}
$$

and

$$
\frac{d \alpha^{F A}}{d \tau_{i}}=-\lambda \frac{p}{\gamma r}, \frac{d \alpha^{F A}}{d \tau_{j}}=\lambda \frac{p}{\gamma r}
$$

so that 
Proposition 1: In the conditions of this model, under FA, (1) investment in the lower-taxing jurisdiction is, at given tax rates, at most as large as under SA, and (2) that investment is at most as sensitive to tax changes as under SA.

Corollary 1: In the conditions of this model, under FA, if the sole criterion of apportionment is not a decision variable of the $\operatorname{MJE}(\lambda=0)$, the distribution of total investment among the jurisdictions is unaffected by changes in tax rates.

\section{b) The Governments}

At the level of public authorities, the problem is the same as previously with the tax bases however redefined accordingly using equations (13) and (14). Then the reaction function are

$$
\tau_{i}^{F A}=\frac{u-s}{2 u-s}\left[\frac{\lambda \alpha_{0}+(1-\lambda) q}{\lambda p} \gamma r+\tau_{j}^{F A}\right]
$$

and

$$
\tau_{j}^{F A}=\frac{u-(1-s)}{2 u-(1-s)}\left[\frac{\lambda\left(1-\alpha_{0}\right)+(1-\lambda)(1-q)}{\lambda p} \gamma r+\tau_{i}^{F A}\right]
$$

with again

$$
1>\frac{d \tau_{i}}{d \tau_{j}}=\frac{u-s}{2 u-s}>0
$$

Comparing the reaction functions (18) and (19) with their counterparts (8) and (9) immediately shows that the slopes are unaffected by the move to FA while the intercepts are either increased $(\lambda<1)$ or unchanged $(\lambda=1)$. Proceeding as previously, thus introducing the sole restriction that $s=.5$, we obtain the following values for the tax rates at Nash equilibrium, to be compared with (10) and (11)

$$
\tau_{i}^{F A}=k\left[\frac{\lambda \alpha_{0}+(1-\lambda) q}{\lambda p}+\frac{u-s}{2 u-s} \frac{\lambda\left(1-\alpha_{0}\right)+(1-\lambda)(1-q)}{\lambda p}\right] \gamma r
$$

and

$$
\tau_{j}^{F A}=k\left[\frac{\lambda\left(1-\alpha_{0}\right)+(1-\lambda)(1-q)}{\lambda p}+\frac{u-s}{2 u-s} \frac{\lambda \alpha_{0}+(1-\lambda) q}{\lambda p}\right] \gamma r
$$

From that comparison, it turns out that

$$
\tau_{i}^{F A}, \tau_{j}^{F A} \geq \tau_{i}^{\circ}, \tau_{j}^{\circ} \Leftrightarrow \lambda \leq 1
$$


Moreover, now

$$
\alpha^{F A}=\alpha_{0}+\frac{u-s}{3 u-2 s} \frac{\lambda\left(1-2 \alpha_{0}\right)+(1-\lambda)(1-2 q)}{\lambda}
$$

which is equal to its counterpart under SA if the sole element in the apportionment formula is property. Especially, for symmetric jurisdictions

$$
\alpha^{F A}=\alpha_{0}, \tau_{i}^{F A}=\tau_{j}^{F A}=\frac{u-s}{u} \frac{q}{\lambda p} \gamma r, s=\alpha_{0}=q=.5
$$

From (13) and (22),

$$
B_{i}^{F A}=\left[\lambda \alpha_{0}+\frac{u-s}{3 u-2 s} \frac{\lambda^{2}\left(1-2 \alpha_{0}\right)+\lambda(1-\lambda)(1-2 q)}{\lambda}+(1-\lambda)(1-q)\right] \frac{p}{r}
$$

and again the tax base under FA equals that under SA if the sole apportionment criterion is the distribution of property.

A tentative conclusion then arises,

Proposition 2: In the conditions of this model, (1) under FA, tax rates at Nash equilibrium, are at least as large as under SA, so that (2) tax competition is at most as strong under FA as under SA.

Corollary 2a: In the conditions of this model, (1) under FA, if the sole criterion of apportionment is the distribution of property, tax rates at Nash equilibrium, tax revenues and social welfare levels are identical as under SA, so that (2) tax competition is as strong under FA as under SA.

Corollary 2b: In the conditions of this model, (1) under FA, if the criteria of apportionment include (viz. reduce to) the distribution of sales (using the destination principle), tax rates at Nash equilibrium are higher than under SA and less dependent on (viz. independent of) MJE decisions, so that (2) tax competition is reduced (viz. eliminated).

So far however, we have left aside tax shifting strategic behaviours which are permitted to MJE's under SA, but most often no longer allowed under FA. Time has come to introduce them and to revise our tentative conclusions accordingly. 


\section{Tax-shifting strategies}

We consider three tax shifting strategies thereafter.

The first one, called Intra-Firm Trade, IFT, consists in transferring goods (at least on paper) from one entity to the other at an exogenously given transfer price in order to allow each entity to serve its own local market. In other words, now, if $q$ is larger than $\alpha$, the quantity $q-\alpha$ is no longer exported by the entity in $j$ to customers in $i$, but it is sold, within the MJE, by entity in $j$ to entity in $i$ in order to be further sold on the $i$ retail market by the local entity of the group. There is thus room for intra-firm trade. In that setting the price used for intrafirm trade purposes is the wholesale price for the good produced and sold by the MJE, also known as the arm's length or full competition price. We note that wholesale price $p^{w}$ with $0<p^{w} \leq p$

A strategic consequence of that new setting - and mutatis mutandis for the other strategies investigated below - is that, in response to tax changes, the firm can now substitute moving real investment, deemed to be a costly activity, with conducting intra-firm trade, supposed to be less costly; therefore it has the opportunity to save cost. Since, for the firm, the cost of redistributing the overall profit between the two local tax bases is reduced, one can expect that, for the jurisdictions, the cost of tax revenue, in terms of tax cut, is also reduced, so that equilibrium tax rates can be higher.

The second strategy consists in shifting a fraction $b$ of the tax base of the active entities to a passive entity located in jurisdiction $k$ where the corporate tax rate $\tau_{k}$ is pre-determined and small; there is no demand for the good in that jurisdiction nor any possibility of setting up a real investment there. Practically the parent entity invests in share an amount $b$ in the passive entity which pays out dividends to its parent; the passive entity is deemed to be located in a jurisdiction whose tax system, despite its attractiveness, does not make it a tax heaven and thus does not disallow dividends from $k$ to be tax exempt in $i$ - notice that within the EU it is enough therefore that $k$ be a Member State. Entity in $k$ makes a loan to each active entity and receives interests which are tax exempt at source but fully taxed in $k$ before being turned onto dividends and repatriated to the parent entity in $i$. The value of $b$ is chosen in such a way that 
the active entities are not convinced of thin capitalisation. In other words, departing $b$ from zero has a cost. That kind of strategy is abundantly formalised in Gerard and Gillard (2004) which talk about inter-modal finance since they allow interest to be turned onto dividend and vice versa at some nodes of their interjurisdictional network - and is similar in spirit to that considered by Mintz and Smart (2004).

The last tax-shifting strategy expands the first one by manipulating the transfer price used within the MJE. The transfer price $p^{*}$ chosen by the firm may be different from the arm's length price $p^{w}$ practiced between independent traders on the wholesale market for the good; however we assume that departing from that price has a cost. There is a large amount of literature on such kind of strategies, let us mention especially Elitzyr and Mintz (1996) and Nielsen , Raimondos-Moller and Schjelderup (2003).

\subsection{Under Separate Accounting}

The problem of the MJE still consists in maximising its value, but now with respect to three variables, $\alpha, p^{*}$ and $b$ which all have a cost, assumed to be quadratic. Next to the cost of redistributing investment, given by equation (3), we have

$$
c\left(p^{*}\right)=\frac{\theta}{2}\left(p^{*}-p^{w}\right)^{2}
$$

and

$$
c(b)=\frac{\beta}{2} b^{2}
$$

Thus the MJE maximises

$$
V=\frac{p}{r}-c(\alpha)-c\left(p^{*}\right)-c(b)-\tau_{i} B_{i}-\tau_{j} B_{j}-\tau_{k} B_{k}
$$

with now

$$
\begin{gathered}
B_{i}=(1-b)\left[q \frac{p}{r}-(q-\alpha) \frac{p^{*}}{r}\right] \\
B_{j}=(1-b)\left[(1-q) \frac{p}{r}+(q-\alpha) \frac{p^{*}}{r}\right]
\end{gathered}
$$

and

$$
B_{k}=b \frac{p}{r}
$$




\section{a) Intra-firm trade}

Suppose tentatively that $\beta, \theta \rightarrow \infty$ so that the MJE does not attempt to channel income through jurisdiction $k$ nor to manipulate the transfer price strategically. The f.o.c. of its program then is

$$
\begin{aligned}
\frac{d V}{d \alpha} & =\left[\tau_{j}-\tau_{i}\right] \frac{p^{w}}{r}-c_{\alpha}^{\prime}=0 \\
& =\left[\tau_{j}-\tau_{i}\right] \frac{p^{w}}{r}-\gamma\left(\alpha-\alpha_{0}\right)=0
\end{aligned}
$$

and

$$
\alpha^{I F T}=\alpha_{0}+\frac{\tau_{j}-\tau_{i}}{\gamma} \frac{p^{w}}{r}
$$

where superscript IFT refers to existence of intra-firm trade, so that

$$
\frac{d \alpha}{d \tau_{i}}=-\frac{p^{w}}{\gamma r}<0, \frac{d \alpha}{d \tau_{j}}=\frac{p^{w}}{\gamma r}>0
$$

Comparison of equations (29) and (30) with their counterparts (5) and (6) shows that introducing intra-firm trade per se - which means here for given values of tax rates and other variables - reduces investment in the lower-taxing jurisdiction and the sensitivity of investment to tax changes as well.

Turning now to the behaviour of local authorities which maximise equation (7) like social welfare functions with the tax bases duly adapted using (26) and (27), we obtain the new reaction functions

$$
\tau_{i}^{I F T}=\frac{u-s}{2 u-s}\left[\frac{\gamma r \alpha_{0}}{p^{w}}+\frac{\gamma r q\left(p-p^{w}\right)}{\left(p^{w}\right)^{2}}+\tau_{j}^{I F T}\right]
$$

and

$$
\tau_{j}^{I F T}=\frac{u-(1-s)}{2 u-(1-s)}\left[\left(1-\alpha_{0}\right) \frac{\gamma r}{p^{w}}+\frac{\gamma r(1-q)\left(p-p^{w}\right)}{\left(p^{w}\right)^{2}}+\tau_{i}^{I F T}\right]
$$


Those two equations are to be compared with equations (8) and (9). That comparison reveals identical slopes but larger intercept - since by definition $p>p^{w}-$ so that the values of the tax rates at Nash equilibrium are larger and tax competition is mitigated.

With the sole restriction that $s=.5$, one obtains indeed that

$$
\tau_{i}^{I F T}=k \frac{\alpha_{0} p^{w}+q\left(p-p^{w}\right)}{\left(p^{w}\right)^{2}} \gamma r+k \frac{u-s}{2 u-s} \frac{\left(1-\alpha_{0}\right) p^{w}+(1-q)\left(p-p^{w}\right)}{\left(p^{w}\right)^{2}} \gamma r
$$

and similarly for the other jurisdiction.

Since, on the one hand, $p>p^{w}$ and, on the other hand, the MJE will never undertake a tax shifting strategy if it has no interest to do so - a participation constrain or incentive compatibility argument - , the following result arises

$$
\tau_{i}^{I F T}, \tau_{j}^{I F T} \geq \tau_{i}^{\circ}, \tau_{j}^{\circ}
$$

subject to the condition that the participation constrain

$$
V^{I F T} \geq V^{\circ}
$$

be satisfied - remember that ${ }^{\circ}$ refers to the benchmark case of section 2. That constrain actually requires that the possible extra amount of tax liabilities generated by the increase of the equilibrium values of the tax rates be offset by a decrease in either the cost of adapting behaviour to new tax rates or the levels of the tax bases, or both. This is to require

$$
c\left(\alpha^{I F T}\right)-T_{i}^{I F T}-T_{j}^{I F T} \leq c\left(\alpha^{\circ}\right)-T_{i}^{\circ}-T_{j}^{\circ}
$$

which can be formally introduced in the program of each jurisdiction using Lagrange multipliers $l_{i}$ and $l_{j}$. That implies reinterpreting $s$ and $(1-s)$ as $s+l_{i}$ and $(1-s)+l_{j}$ respectively. Equations (31) and (32) immediately show that tax rates at Nash equilibrium then go down since both the intercept and slope are decreased.

Under the additional assumption of a symmetric economy, the equilibrium value of the tax rate is

$$
\tau_{i}^{I F T}=\tau_{j}^{I F T}=\frac{u-s}{u}\left[\frac{\gamma r q}{p^{w}} \frac{p}{p^{w}}\right], q=\alpha_{0}=s=.5
$$


unambiguously larger than in the corresponding case of section 2 if the participation constrain is fulfilled $\left(l_{i}=l_{j}=0\right)$. Otherwise $s$ is substituted with $s+l_{i}$, thus it goes up implying that the Nash equilibrium values of the tax rates go down.

As a conclusion,

Proposition 3: In the conditions of this model, under SA, allowing for intra-firm trade (1) reduces investment in the lower-taxing jurisdiction, at given tax rates, and the sensitivity of investment distribution to tax changes, (2) increases the tax rates at Nash equilibrium unambiguously if the participation constrain is satisfied.

\section{b) A profitable detour}

Let us now relax the assumption that $\beta \rightarrow \infty$. Aside for the transfer pricing issue, the competition between an active jurisdiction like $i$ or $j$ and passive jurisdiction $k$ to have the tax base produced in $i$ or $j$ taxed on its territory is the case in mind in Mintz and Smart (2004). In our model, that means that a second f.o.c. is now at work

$$
\begin{aligned}
\frac{d V}{d b} & =\left(\tau_{i}-\tau_{k}\right)\left[q \frac{p}{r}-(q-\alpha) \frac{p^{w}}{r}\right] \\
& +\left(\tau_{j}-\tau_{k}\right)\left[(1-q) \frac{p}{r}+(q-\alpha) \frac{p^{w}}{r}\right]-c^{\prime}{ }_{b}=0
\end{aligned}
$$

with $c^{\prime}{ }_{b}=\beta b$, implying that

$$
b=\frac{\tau_{i}-\tau_{k}}{\beta}\left[q \frac{p}{r}-(q-\alpha) \frac{p^{w}}{r}\right]+\frac{\tau_{j}-\tau_{k}}{\beta}\left[(1-q) \frac{p}{r}+(q-\alpha) \frac{p^{w}}{r}\right]
$$

which is to be compared with equation (3) in Mintz and Smart (2004). Equation (29) becomes now

$$
\alpha^{k}=\alpha_{0}+\frac{\left(\tau_{j}-\tau_{i}\right)(1-b)}{\gamma} \frac{p^{w}}{r}
$$

Examination of that equation immediately shows that the rise of a competition between active and passive jurisdictions to get the tax base generated in the former taxed on the territory of the latter is likely to reduce the investment in jurisdiction $i$ assumed still to tax at a lower rate than $j$. The weight of the tax rate in $i$ and $j$ in determining the distribution of investment between the active entities goes down as long as $b$ increases, so that the game between the 
two active jurisdictions is progressively substituted by a game between active and passive jurisdictions. In other terms we see that the sensitivity of the distribution of investment to tax changes in the active jurisdictions decreases as $b$ goes up and vanishes if $b$ equals unity.

However in that latter case, the active entities risk to be convinced of thin capitalisation; therefore, even if money can be channelled at zero transfer cost, that cost can be considered being infinity when some threshold is by-passed. In line with that, one can reasonably consider that

$$
\begin{aligned}
\beta & =0, b \leq b^{*} \\
& \rightarrow \infty, b>b^{*}
\end{aligned}
$$

with $b^{*}$ the thin capitalisation threshold. Then $b$ has to be substituted with $b^{*}$ in equation (35).

That case clearly shows that the investment in the lower-taxing jurisdiction is further reduced by that opportunity of tax shifting, confirming point (1) of Proposition 3 above.

Turning to the maximisation of social welfare functions, we obtain

$$
\tau_{i}^{k}=\frac{u-s}{2 u-s}\left[\frac{\gamma r \alpha_{0}}{\left(1-b^{*}\right) p^{w}}+\frac{\gamma r q\left(p-p^{w}\right)}{\left(1-b^{*}\right)\left(p^{w}\right)^{2}}+\tau_{j}^{k}\right]
$$

and similarly for $j$ so that equilibrium values of the tax rates are now higher in the active jurisdictions.

However, in the game under consideration, $b^{*}$ is taken as given. Actually it could be an instrument in the game between active and passive jurisdictions, the active jurisdictions reducing the value of that parameter in order to prevent interest outflows.

Moreover, with the sole restriction that $s=.5$, one obtains indeed that

$$
\tau_{i}^{k}=k \frac{\gamma r \alpha_{0} p^{w}+\gamma r q\left(p-p^{w}\right)}{\left(1-b^{*}\right)\left(p^{w}\right)^{2}}+k \frac{u-s}{2 u-s} \frac{\gamma r\left(1-\alpha_{0}\right) p^{w}+\gamma r(1-q)\left(p-p^{w}\right)}{\left(1-b^{*}\right)\left(p^{w}\right)^{2}}
$$

and similarly for the other jurisdiction. Then point (2) of Proposition 3 is confirmed. Moreover, if the active jurisdictions are symmetric,

$$
\tau_{i}^{k}=\tau_{j}^{k}=\frac{u-s}{u}\left[\frac{\gamma r q}{\left(1-b^{*}\right) p^{w}} \frac{p}{p^{w}}\right], q=\alpha_{0}=s=.5
$$




\section{c) Transfer Price Manipulation}

Now assume that $\theta$ no longer tends to infinity but, to keep the model tractable, suppose that $\beta$ does it again so that profitable detours are ruled out. The two decision variables of the MJE are now $\alpha$ the distribution of the investment, and $p^{*}$ the transfer price, subject to the condition that $0<p^{*} \leq p$. Notice that $p^{*}$ is the price decided by the MJE for intra-firm trade while $p^{w}$ is the wholesale price for the good under consideration, thus the price practiced for trade between independent firms. The cost of departing $p^{*}$ from $p^{w}$ is given by equation (23) above.

Maximisation of the value of the firm, see equation (25), provides us with the following expressions derived from the f.o.c

$$
\alpha^{T P M}=\alpha_{0}+\frac{\tau_{j}-\tau_{i}}{\gamma} \frac{p^{*}}{r}
$$

and

$$
p^{*}=p^{w}+\frac{\tau_{j}-\tau_{i}}{\theta} \frac{\alpha-q}{r}
$$

The former expression is similar to (29) but with $p^{*}$ substituted for $p^{w}$. Therefore, starting with $p^{*}=p^{w}$ and an initial distribution of investment $\alpha_{0}$ supposed e.g. identical to that of sales, $\alpha_{0}=q$, if the tax rate in $i$ is smaller than in $j$, the investment and production in jurisdiction $i$ increases. Moreover, since the best interest of the MJE is to have the largest amount of tax base in $i$ and since entity in $i$ is the net producer of goods, the MJE increases the transfer price $p^{*}$ above $p^{w}$. As a consequence, the investment in $i$ is larger now than when transfer price might not be manipulated. The converse situation appears when the tax rate becomes smaller in $j$. However, for $p^{*}$ is upper bounded by $p$, the relative investment in $i$ will not be larger than in the initial model, at least at given tax rates.

The conclusions of the IFT case then remain valid under the present TPM setting. 


\subsection{Under Formulary Apportionment}

Under Consolidation and Formulary Apportionment we are back to the FA case investigated above in section 2, assuming that the passive entity located in jurisdiction $k$ is integrated in the consolidation perimeter.

It turns out that

Proposition 4 : By ruling out tax shifting strategies, move to FA with property as sole criterion of apportionment (1) pushes up investment in the lower-taxing jurisdiction at given tax rates and (2) boosts tax competition.

Corollary 4 : If another criterion is introduced, like sales (using the destination principle), deemed to be independent of firm decision, the effect of the move is ambiguous.

The problem indeed is then to compare e.g. equation (38) with equation (20), and also the corresponding equations for a symmetric economy. In the first case moving to FA will boost tax competition if

$$
\begin{aligned}
& \frac{\alpha_{0} p^{w}+q\left(p-p^{w}\right)}{\left(1-b^{*}\right)\left(p^{w}\right)^{2}}+\frac{u-s}{2 u-s} \frac{\left(1-\alpha_{0}\right) p^{w}+(1-q)\left(p-p^{w}\right)}{\left(1-b^{*}\right)\left(p^{w}\right)^{2}} \\
& \geq \frac{\lambda \alpha_{0}+(1-\lambda) q}{\lambda^{2} p}+\frac{u-s}{2 u-s} \frac{\lambda\left(1-\alpha_{0}\right)+(1-\lambda)(1-q)}{\lambda^{2} p}
\end{aligned}
$$

To illustrate the meaning of condition (41) suppose that $p^{w}=p$ and that $b^{*}>0$, then

$$
\tau_{i}^{I F T} \geq \tau_{i}^{F A} \Leftrightarrow b^{*}>0, s=.5
$$

and the elimination of a profitable detour increases tax competition between remaining competitors, pushing the tax rates down. Otherwise, in case of symmetric jurisdictions,

$$
\tau_{i}^{I F T} \geq \tau_{i}^{F A} \Leftrightarrow \lambda^{2} p^{2} \geq\left(p^{w}\right)^{2}, s=\alpha_{0}=q=.5
$$

which depends on the value of $\lambda$ decided by the authorities of the jurisdictions. Clearly, if only sales matter to distribute the consolidated tax base, in this model, the move to FA increases the equilibrium tax rates anyway while if only the distribution of property is used, tax competition is boosted and the move to FA reduces the tax rates. 
A qualification needs however to be recognised. The governments at work in this model are not primarily interested by real investment but by the welfare of the shareholder and the level of tax revenues. Therefore the outcome of the exercise conducted so far should be compared with that of an alternative one including $\alpha$ (viz. $(1-\alpha)$ ) as such in the social welfare function.

However, the exercise conducted above can also be regarded as a useful prolegomenon for an investigation of the feasibility of the move to FA in an area like the EU where decisions in tax matters require unanimity. Since, clearly, that move implies that $T_{k}^{F A}$ vanishes, it is a key issue that e.g. $\lambda$, and thus the apportionment formula, be chosen in such a way that

$$
T_{i}^{F A}+T_{j}^{F A} \geq T_{i}^{k}+T_{j}^{k}+T_{k}^{k}
$$

in order to allow for a side payment from jurisdictions $i$ and $j$ to jurisdiction $k$.

\section{Occurrence of losses}

Losses deserve a specific treatment since their interjurisdictional compensation among affiliates of the MJE not only forms part of the consolidation mechanism behind FA, but can also be set up within the SA framework (see Gerard and Weiner, 2003, 2005).

Therefore, let us expand the model used in section 3.1. a) to include the occurrence of losses.

First assume that there are four states of nature, two in each jurisdiction. If a good state of nature occurs in a given jurisdiction, an event of probability $\omega$, then the profit observed above also occurs there. However, if a bad state of nature occurs, the profit is replaced by a loss denoted $\varepsilon$, actually $\varepsilon_{i}$ and $\varepsilon_{j}$ respectively. Combining the various possibilities, the expected value of the MJE before tax can be rewritten, 


$$
\begin{aligned}
V^{B T} & =\frac{p}{r} \omega^{2} \\
& +\left[\frac{p q}{r}-\frac{p^{w}(q-\alpha)}{r}-\varepsilon_{j}\right] \omega(1-\omega) \\
& +\left[\frac{p(1-q)}{r}+\frac{p^{w}(q-\alpha)}{r}-\varepsilon_{i}\right] \omega(1-\omega) \\
& -\left(\varepsilon_{i}+\varepsilon_{j}\right)(1-\omega)^{2}-c(\alpha) \\
& =\frac{p}{r} \omega-\left(\varepsilon_{i}+\varepsilon_{j}\right)(1-\omega)-c(\alpha)
\end{aligned}
$$

We assume that the probability of occurrence of a loss is small but that the loss itself is large. Then, although overall profit of the MJE becomes negative when losses appear in one jurisdiction, the expected value of the MJE is positive.

\subsection{Under Separate Accounting}

We begin by assuming that loss offset is not allowed. We then introduce this possibility. Notice that in the discussion which follows, we use the term value to refer to the expected value.

\section{a) No loss offset}

In such a situation, the value of the MJE becomes

$$
\begin{aligned}
V & =\frac{p}{r} \omega-\left(\varepsilon_{i}+\varepsilon_{j}\right)(1-\omega)-c(\alpha)-\omega \tau_{i}\left[q \frac{p}{r}-(q-\alpha) \frac{p^{w}}{r}\right] \\
& -\omega \tau_{j}\left[(1-q) \frac{p}{r}+(q-\alpha) \frac{p^{w}}{r}\right]
\end{aligned}
$$

so that, from the f.o.c. of its maximisation w.r.t. $\alpha$

$$
\alpha=\alpha_{0}+\frac{\omega\left(\tau_{j}-\tau_{i}\right)}{\gamma} \frac{p^{w}}{r}
$$

and

$$
\frac{d \alpha}{d \tau_{i}}=-\omega \frac{p^{w}}{\gamma r}, \frac{d \alpha}{d \tau_{j}}=\omega \frac{p^{w}}{\gamma r}
$$

Then, comparing the equations just above with those of section 2, we have 
Proposition 5 : Under SA, when interjurisdictional compensation of losses is not allowed, (1) investment in the lower-taxing active jurisdiction, at given tax rates, and (2) sensitivity of investment location to tax rates in the active jurisdictions, are both reduced.

The rationale behind that result is simple: the expected return on an investment in $i$ has no longer a probability equal to one but a probability equal to $\omega<1$. Then, for the firm, the expected return of departing from $\alpha_{0}$ is smaller while its cost is unchanged.

Government policies turn out to be characterised by

$$
\frac{d W_{i}}{d \tau_{i}}=(u-s) \omega\left[q \frac{p}{r}-(q-\alpha) \frac{p^{w}}{r}\right]+u \tau_{i} \omega \frac{p^{w}}{r} \frac{d \alpha}{d \tau_{i}}=0
$$

for jurisdiction $i$ and similarly for the other jurisdiction. Then

$$
\tau_{i}^{N L O}=\frac{u-s}{2 u-s}\left[\frac{\gamma r q\left(p-p^{w}\right)}{\omega\left(p^{w}\right)^{2}}+\frac{\gamma r \alpha_{0}}{\omega p^{w}}+\tau_{j}\right]
$$

or, assuming $s=.5$, see equation (33)

$$
\tau_{i}^{N L O}=\frac{\tau_{i}^{I F T}}{\omega}
$$

Inspection of equation (46) shows that the intercepts of the reaction functions are larger than in the absence of risk of loss while the slopes are again identical so that equilibrium tax rates are higher, which is confirmed by equation (47). We can therefore state that

Proposition 6 : Under SA, when interjurisdictional compensation of losses is not allowed, tax competition between active jurisdictions is reduced, pushing up the corresponding tax-rate values at Nash equilibrium.

\section{b) Loss offset}

We now allow the MJE to compensate losses among its affiliates. Since we have assumed that a loss in either jurisdiction $i$ or jurisdiction $j$ has the consequence that the overall profit of the firm vanishes, interjurisdictional compensation of losses implies that a loss in a given 
jurisdiction involves the disappearance of taxable profit in the other. Then the value of the MJE becomes

$$
\begin{aligned}
V & =\frac{p}{r} \omega-\left(\varepsilon_{i}+\varepsilon_{j}\right)(1-\omega)-c(\alpha)-\omega^{2} \tau_{i}\left[q \frac{p}{r}-(q-\alpha) \frac{p^{w}}{r}\right] \\
& -\omega^{2} \tau_{j}\left[(1-q) \frac{p}{r}+(q-\alpha) \frac{p^{w}}{r}\right]
\end{aligned}
$$

and, proceeding as previously,

$$
\begin{gathered}
\alpha=\alpha_{0}+\omega^{2} \frac{\tau_{j}-\tau_{i}}{\gamma} \frac{p^{w}}{r} \\
\frac{d \alpha}{d \tau_{i}}=-\omega^{2} \frac{p^{w}}{\gamma r}, \frac{d \alpha}{d \tau_{j}}=\omega^{2} \frac{p^{w}}{\gamma r}
\end{gathered}
$$

Comparing (49) and (50) with (44) and (45) immediately shows that investment in the lowertaxing active jurisdiction is per se further reduced, and the sensitivity of investment distribution to changes in tax rates as well. This is due to the fact that now, investing in the higher-taxing jurisdiction is a way for the MJE to protect its expected value against losses in the other jurisdiction. Indeed, losses occurring in one jurisdiction imply that less tax is paid in the other: extra investment in the higher-taxing jurisdiction is an insurance premium and the tax gain in case of loss in the other jurisdiction is the insurance compensation. Thus,

Proposition 7 : Under SA, when interjurisdictional compensation of losses is permitted, (1) investment in the lower-taxing active jurisdiction, at given tax rates, as well as (2) the sensitivity of investment location to tax rates in the active jurisdictions are further reduced. Extra investment in the higher-taxing jurisdiction acts as an insurance premium allowing for greater tax deductibility when losses occur in the other jurisdiction.

Similarly, turning to the tax authorities, we observe a further increase in the intercepts of the reaction functions, e.g, for the tax rate of jurisdiction $i$

$$
\tau_{i}^{L O}=\frac{u-s}{2 u-s}\left[\frac{\gamma r q\left(p-p^{w}\right)}{\omega^{2}\left(p^{w}\right)^{2}}+\frac{\gamma r \alpha_{0}}{\omega^{2} p^{w}}+\tau_{j}\right]
$$

while the slopes of the reaction functions remain unchanged. And

$$
\tau_{i}^{L O}=\frac{\tau_{i}^{N L O}}{\omega}=\frac{\tau_{i}^{I F T}}{\omega^{2}}, s=.5
$$


Consequently,

Proposition 8 : Under SA, when interjurisdictional compensation of losses is permitted, tax competition between active jurisdictions is further reduced, pushing up again corresponding tax-rate values at Nash equilibrium.

\subsection{Under Formulary Apportionment}

The previous paragraph shows the effect of the interjurisdictional compensation of losses, which is also the tax-shifting feature of the consolidation under FA. We also know from section 3 that moving from SA to FA rules out other, or most other, tax-shifting opportunities. This produces the result that the outcome of a move from SA with compensation of losses to FA will consist in a possibly boosted sensitivity of investment to tax rates and an increased tax competition, at least when apportionment is conducted according to the distribution of investment (property criterion). When apportionment also follows the distribution of sales, the results previously obtained under the corresponding assumptions hold.

Therefore, if the apportionment criterion is the sole distribution of property, the value of the MJE now is

$$
V=\frac{p}{r} \omega-\left(\varepsilon_{i}+\varepsilon_{j}\right)(1-\omega)-c(\alpha)-\tau_{i} B_{i}-\tau_{j} B_{j}
$$

with

$$
\begin{gathered}
B_{i}=[\lambda \alpha+(1-\lambda) q] B \\
B_{j}=[\lambda(1-\alpha)+(1-\lambda)(1-q)] B
\end{gathered}
$$

and

$$
B=\omega^{2} \frac{p}{r}
$$

with the last three equations to be compared with (13) to (15).

It turns out that

$$
\alpha^{F A / \omega}=\alpha_{0}+\lambda \omega^{2} \frac{\tau_{j}-\tau_{i}}{\gamma} \frac{p}{r}
$$


As a consequence,

Proposition 9 : Under FA with taxable profit distributed solely according to the distribution of the investment $(\lambda=1)$, (1) the proportion of investment located in the lower-taxing jurisdiction and the sensitivity of investment to changes in tax rates become smaller when risk of losses is taken into account, but (2) a move from SA to FA increases both the proportion and the sensitivity.

Similarly, from the maximisation of the social welfare functions,

$$
\tau_{i}^{F A / \omega}=\frac{u-s}{2 u-s}\left[\frac{\lambda \alpha_{0}+(1-\lambda) q}{\lambda^{2} \omega^{2} p} \gamma r+\tau_{j}\right]
$$

or

$$
\tau_{i}^{F A / \omega}=\frac{\tau_{i}^{F A}}{\omega^{2}}, s=.5
$$

and

$$
\tau_{i}^{F A / \omega}=\frac{\tau_{i}^{F A}}{\omega^{2}}<\frac{\tau_{i}^{I F T}}{\omega^{2}}, s=.5, \lambda=1
$$

so that,

Proposition 10 : Under FA with taxable profit distributed solely according to the distribution of the investment $(\lambda=1)$, (1) the tax rates at Nash equilibrium are larger when risk of losses is taken into account - accordingly, tax competition is then reduced -, but (2) moving from SA to FA can reduce these tax rates, and the degree of tax competition can go up, doing it actually when the apportionment formula is solely based on the distribution of the property.

\section{Notice that}

Remarks : (a) In Propositions 9 and 10, the (2) element is due to fact that the move to FA rules out the tax consequence of intra-firm trade; (b) as previously, if sales, measured at destination, are introduced in the apportionment formula $(\lambda<1)$, results become ambiguous. 


\section{Conclusion}

In this paper we have investigated a reform of the taxation of multijurisdictional enterprises, consisting in a move from Separate Accounting, SA, to Formulary Apportionment, FA. We have conducted this study in an extended framework which embodies the existence of transfer-pricing strategies and other tax-shifting opportunities on the one hand, the risk of occurrence of losses and the possibility of interjurisdictional loss-offset under both SA and FA mechanisms on the other hand. We have gathered our findings in a series of propositions supported by our model.

To summarise, under Separate Accounting, transfer pricing strategies and other tax-shifting opportunities reduce the fraction of investment in the lower-taxing active jurisdiction, the sensitivity of the distribution of investment to tax changes and the degree of interjurisdictional tax competition as well; as a result, tax rates at Nash equilibrium go up subject to the condition that a participation constrain of the MJE be satisfied.

However, moving to Formulary Apportionment eliminates such opportunities and acts as an incentive to increase the fraction of investment in the lower-taxing active jurisdiction, the sensitivity of the distribution of investment to tax changes and the degree of interjurisdictional tax competition. In consequence, the reform can boost tax competition, and it does it if the tax base is apportioned on the sole criterion of the distribution of property. When the distribution of sales, a variable not under control of the firm in the paper, is introduced in the apportionment formula, the result can become ambiguous. Notice that such a distinction is a simple way to introduce variability in the mobility of - or the elasticity to - the tax base under FA.

On the other hand, permitting the MJE to compensate losses among its affiliates located in different jurisdictions allows it to use a tax-shifting and insurance device and thus, under Separate Accounting, reduces the fraction of investment in the lower-taxing active jurisdiction, the sensitivity of the distribution of investment to tax changes and the degree of interjurisdictional tax competition as well. In consequence, tax rates at Nash equilibrium go up. A subsequent move to Formulary Apportionment per se does not alter this result; however since it rules out intra-firm trade, which is a tax shifting opportunity, it can boost tax 
competition, and it actually does it if the apportionment formula only depends on the distribution of property (investment) - otherwise the result can be ambiguous.

A qualification needs however to be recognised. The governments at work in this model are not primarily interested by real investment but by the welfare of the shareholder and the level of tax revenues. Therefore the outcome of the exercise conducted so far should be compared with that of an alternative one including real domestic investment as such in the social welfare function.

However, the exercise conducted in this paper can also be regarded as a useful prolegomenon for an investigation of the feasibility of the move to FA in an area like the EU where decisions in tax matters require unanimity. Since, clearly, that move implies that tax revenue in the passive jurisdiction vanishes, it is a key issue that the apportionment formula be chosen in such a way that total tax revenues do not fall, in order to allow the active jurisdictions to offset the passive revenue losing ones.

To sum up, Table 1 below allows the reader to compare tax rates at Nash equilibrium for a symmetric economy, defining the case of no risk, SA and no intra-firm trade, as a benchmark.

Table 1 - Tax rates at Nash equilibrium for a symmetric economy.

\begin{tabular}{|c|c|c|c|}
\hline & $\begin{array}{c}\text { Separate Accounting } \\
\text { No intra-firm trade } \\
\text { allowed (section 2) }\end{array}$ & $\begin{array}{c}\text { Separate Accounting } \\
\text { Intra-firm trade allowed } \\
\text { (sections 3.1a and 4) }\end{array}$ & $\begin{array}{c}\text { Formulary } \\
\text { Apportionment }\end{array}$ \\
\hline No risk & $\tau_{s}, s=i, j$ & $\tau_{s}\left(\frac{p}{p^{w}}\right)^{2}$ & $\tau_{s} \frac{1}{\lambda^{2}}$ \\
\hline Risk, no loss offset & $\tau_{s} \frac{1}{\omega}$ & $\tau_{s} \frac{1}{\omega}\left(\frac{p}{p^{w}}\right)^{2}$ & $\tau_{s} \frac{1}{\lambda^{2} \omega}$ \\
\hline Risk, loss offset & $\tau_{s} \frac{1}{\omega^{2}}$ & $\tau_{s} \frac{1}{\omega^{2}}\left(\frac{p}{p^{w}}\right)^{2}$ & $\tau_{s} \frac{1}{\lambda^{2} \omega^{2}}$ \\
\hline
\end{tabular}

$\left(0 \leq p^{w} \leq p ; 0 \leq \omega, \lambda \leq 1\right)$

There are lessons for the conduct of fiscal policy suggested by the results in this paper, and especially two. On the one hand, interjurisdictional compensation of losses is a desirable feature per se, and remains so even if the move to Formulary Apportionment is not completed. 
On the other hand, the distribution of investment as a criterion for apportioning the tax base of the MJE makes the attracting of investment onto its territory still more desirable for a government and is therefore likely to boost tax competition. Such feature appears less and might even be reversed when apportionment is also conducted according to criteria which are less affected by the MJE behaviour, or which cannot be affected by its behaviour. Therefore the selection of criteria is an especially sensible issue - see Goolsbee and Maydew (2000) for the US experience. As mentioned above that selection is even more important in the EU where decisions in tax matters require unanimity of Member States.

Avenues for further and related research are numerous. They include the investigation of the effect of the reform on the distribution of tax revenue among jurisdictions which host active and passive entities respectively and, in consequence, of the decision process at interjurisdictional level that is capable of making such reform acceptable to a group of jurisdictions. They also include the determination of the consolidation perimeter and the MJE decision as to whether to include or exclude some affiliates within that perimeter.

\section{References}

Anand, B, and R. Sansing, 2000, “The Weighting Game: Formula Apportionment as an Instrument of Public Policy”, National Tax Journal, 53, 183-199.

Bartelsman, E. and R. Beetsma, 2003, "Why Pay More? Corporate Tax Avoidance through Transfer Pricing in OECD Countries”, Journal of Public Economics, 87, 2225-2252.

Cnossen, S., 2002, "Tax Policy in the European Union: A Review of Issues and Options”, CESifo Working Paper, 758, Munich.

Devereux, M., 2004, "Debating Proposed Reforms of the Taxation of Corporate Income in the European Union”, International Tax and Public Finance, 11, 71-89.

Eggert W. and G. Schjelderup, 2003, "Symmetric tax competition under formula apportionment”, Journal of Public Economic Theory, 5, 437-444.

Elitzyr, R. and J. Mintz, 1996, “Transfer pricing rules and corporate tax competition”, Journal of Public Economics, 60, 401-422.

European Commission, 2003, An Internal Market without Company Tax Obstacles, Achievements, Ongoing Initiatives and Remaining Challenges, COM(2003)726final, Brussels.

European Commission, 2001, Company Taxation in the Internal Market, COM(2001)582final, Brussels.

Gérard, M. and M.-F. Gillard, 2004, "Taxation, financial intermodality and the least taxed path for circulating income within a multinational enterprise”, Annales d'Economie et de Statistique, 75/76, 89-107.

Gérard, M. and J. Weiner, 2003, "Cross-border loss offset and formulary apportionment: How do they affect multijurisdictional firm investment spending and interjurisdictional tax competition?”, CESifo Working paper, 1004, Munich. 
Gérard, M. and J. Weiner, 2005, “Comment la compensation internationale des pertes et la répartition proportionnelle des revenus imposables peuvent affecter les choix des multinationales et la concurrence fiscale”, Economie et Prévision, forthcoming.

Goolsbee A. and E. Maydew, 2000, "Coveting thy neighbor's manufacturing: the dilemma of state income apportionment”, Journal of Public Economics, 75, 125-143.

Gordon, R. and J. Wilson, 1986, "An examination of multijurisdictional corporate income taxation under formula apportionment”, Econometrica, 54, 1357- 1373.

Hellerstein J., 1993, "Federal Income Taxation of Multinationals: Replacement of Separate Accounting with Formulary Apportionment”, Tax Notes, 60, 1131-1145.

Hellerstein, W. and C. McLure, 2004, "The European Commission's Report on Company Income Taxation: What the EU Can Learn from the Experience if the US States”, International Tax and Public Finance, 11, 199-220.

Kolmar,M. and A. Wagener, 2004, The Role of the Tax Base in Tax Competition with Formula Apportionment, University of Vienna, mimeo.

Mintz, J., 2004, “Corporate Tax Harmonization in Europe: It’s All About Compliance” International Tax and Public Finance, 11, 221-234.

Mintz, J. and M. Smart, 2004, "Income shifting, investment, and tax competition: Theory and evidence from provincial taxation in Canada”, Journal of Public Economics, 88, 1149-1168.

Nielsen S., P. Raimondos-Moller P. and G. Schjelderup, 2003, "Formula apportionment and transfer pricing under oligopolistic competition”, Journal of Public Economic Theory, 5, 419-437.

Nielsen, Søren Bo, Pascalis Raimondos-Møller, and Guttorm Schjelderup, 2004, “Company Taxation and Tax Spillovers: Separate Accounting versus Formula Apportionment" Department of Economics, Copenhagen Business School, mimeo.

Schjelderup, G., and L. Sorgard, 1997, "Transfer Pricing as a Strategic Device for Decentralized

Multinationals", International Tax and Public Finance, 4, 277-290.

Sorensen, P., 2004, "Company tax reform in the European Union”, International Tax and Public Finance, 11, 91-115.

Pethig, R. and A. Wagener, 2003, "Profit Tax Competition and Formula Apportionment", CESifo Working Paper, 1010, Munich.

Unice, 2000, “Memorandum on cross border company taxation obstacles in the single market”, Unice, Brussels.

Weiner, J., 2002, "Would Introducing Formula Apportionment in the European Union Be a Dream Come True or the EU's Worst Nightmare?”, Ifo Studien, 48, 419-432.

Weiner, J., and M. Gérard, 2004, “Cross border loss offset, uncertainty, and formulary apportionment: A contribution to the European debate on the taxation of multinationals", Proceedings of the National Tax Association, 2003.

Wellisch, D., 2004, "Taxation under Formula Apportionment - Tax Competition, Tax Incidence, and the Choice of Apportionment Factors", Finanzarchiv, 60, 24-41.

Wildasin, D., 2000, "State and Provincial Corporate Income Taxation, Current Practice and Policy Issues for the United States and Canada”, Canadian Tax Journal, 48, 424-441.

Wilson, J., 1999, “Theories of Tax Competition”, National Tax Journal, 52, 269-304. 


\section{CESifo Working Paper Series}

(for full list see www.cesifo-group.de)

1461 Steffen Huck, Kai A. Konrad and Wieland Müller, Merger without Cost Advantages, May 2005

1462 Louis Eeckhoudt and Harris Schlesinger, Putting Risk in its Proper Place, May 2005

1463 Hui Huang, John Whalley and Shunming Zhang, Trade Liberalization in a Joint Spatial Inter-Temporal Trade Model, May 2005

1464 Mikael Priks, Optimal Rent Extraction in Pre-Industrial England and France - Default Risk and Monitoring Costs, May 2005

1465 François Ortalo-Magné and Sven Rady, Heterogeneity within Communities: A Stochastic Model with Tenure Choice, May 2005

1466 Jukka Pirttilä and Sanna Tenhunen, Pawns and Queens Revisited: Public Provision of Private Goods when Individuals make Mistakes, May 2005

1467 Ernst Fehr, Susanne Kremhelmer and Klaus M. Schmidt, Fairness and the Optimal Allocation of Ownership Rights, May 2005

1468 Bruno S. Frey, Knight Fever - Towards an Economics of Awards, May 2005

1469 Torberg Falch and Marte Rønning, The Influence of Student Achievement on Teacher Turnover, May 2005

1470 John Komlos and Peter Salamon, The Poverty of Growth with Interdependent Utility Functions, May 2005

1471 Hui Huang, Yi Wang, Yiming Wang, John Whalley and Shunming Zhang, A Trade Model with an Optimal Exchange Rate Motivated by Current Discussion of a Chinese Renminbi Float, May 2005

1472 Helge Holden, Lars Holden and Steinar Holden, Contract Adjustment under Uncertainty, May 2005

1473 Kai A. Konrad, Silent Interests and All-Pay Auctions, May 2005

1474 Ingo Vogelsang, Electricity Transmission Pricing and Performance-Based Regulation, May 2005

1475 Spiros Bougheas and Raymond Riezman, Trade and the Distribution of Human Capital, June 2005 
1476 Vesa Kanniainen, Seppo Kari and Jouko Ylä-Liedenpohja, The Start-Up and Growth Stages in Enterprise Formation: The "New View" of Dividend Taxation Reconsidered, June 2005

1477 M. Hashem Pesaran, L. Vanessa Smith and Ron P. Smith, What if the UK had Joined the Euro in 1999? An Empirical Evaluation Using a Global VAR, June 2005

1478 Chang Woon Nam and Doina Maria Radulescu, Effects of Corporate Tax Reforms on SMEs' Investment Decisions under the Particular Consideration of Inflation, June 2005

1479 Panos Hatzipanayotou, Sajal Lahiri and Michael S. Michael, Globalization, CrossBorder Pollution and Welfare, June 2005

1480 John Whalley, Pitfalls in the Use of Ad valorem Equivalent Representations of the Trade Impacts of Domestic Policies, June 2005

1481 Edward B. Barbier and Michael Rauscher, Trade and Development in a Labor Surplus Economy, June 2005

1482 Harrie A. A. Verbon and Cees A. Withagen, Tradable Emission Permits in a Federal System, June 2005

1483 Hendrik Hakenes and Andreas Irmen, On the Long-Run Evolution of Technological Knowledge, June 2005

1484 Nicolas Schmitt and Antoine Soubeyran, A Simple Model of Brain Circulation, June 2005

1485 Carsten Hefeker, Uncertainty, Wage Setting and Decision Making in a Monetary Union, June 2005

1486 Ondřej Schneider and Jan Zápal, Fiscal Policy in New EU Member States - Go East, Prudent Man!, June 2005

1487 Christian Schultz, Virtual Capacity and Competition, June 2005

1488 Yvan Lengwiler and Elmar Wolfstetter, Bid Rigging - An Analysis of Corruption in Auctions, June 2005

1489 Johannes Becker and Clemens Fuest, Does Germany Collect Revenue from Taxing Capital Income?, June 2005

1490 Axel Dreher and Panu Poutvaara, Student Flows and Migration: An Empirical Analysis, June 2005

1491 Bernd Huber and Marco Runkel, Interregional Redistribution and Budget Institutions under Asymmetric Information, June 2005

1492 Guido Tabellini, Culture and Institutions: Economic Development in the Regions of Europe, July 2005 
1493 Kurt R. Brekke and Michael Kuhn, Direct to Consumer Advertising in Pharmaceutical Markets, July 2005

1494 Martín Gonzalez-Eiras and Dirk Niepelt, Sustaining Social Security, July 2005

1495 Alfons J. Weichenrieder, (Why) Do we need Corporate Taxation?, July 2005

1496 Paolo M. Panteghini, S-Based Taxation under Default Risk, July 2005

1497 Panos Hatzipanayotou and Michael S. Michael, Migration, Tied Foreign Aid and the Welfare State, July 2005

1498 Agata Antkiewicz and John Whalley, BRICSAM and the Non-WTO, July 2005

1499 Petr Hedbávný, Ondřej Schneider and Jan Zápal, A Fiscal Rule that has Teeth: A Suggestion for a 'Fiscal Sustainability Council' underpinned by the Financial Markets, July 2005

1500 J. Atsu Amegashie and Marco Runkel, Sabotaging Potential Rivals, July 2005

1501 Heikki Oksanen, Actuarial Neutrality across Generations Applied to Public Pensions under Population Ageing: Effects on Government Finances and National Saving, July 2005

1502 Xenia Matschke, Costly Revenue-Raising and the Case for Favoring Import-Competing Industries, July 2005

1503 Horst Raff and Nicolas Schmitt, Why Parallel Trade may Raise Producers Profits, July 2005

1504 Alberto Bisin and Piero Gottardi, Efficient Competitive Equilibria with Adverse Selection, July 2005

1505 Peter A. Zadrozny, Necessary and Sufficient Restrictions for Existence of a Unique Fourth Moment of a Univariate GARCH(p,q) Process, July 2005

1506 Rainer Niemann and Corinna Treisch, Group Taxation, Asymmetric Taxation and Cross-Border Investment Incentives in Austria, July 2005

1507 Thomas Christiaans, Thomas Eichner and Ruediger Pethig, Optimal Pest Control in Agriculture, July 2005

1508 Biswa N. Bhattacharyay and Prabir De, Promotion of Trade and Investments between China and India: The Case of Southwest China and East and Northeast India, July 2005

1509 Jean Hindriks and Ben Lockwood, Decentralization and Electoral Accountability: Incentives, Separation, and Voter Welfare, July 2005

1510 Michelle R. Garfinkel, Stergios Skaperdas and Constantinos Syropoulos, Globalization and Domestic Conflict, July 2005 
1511 Jesús Crespo-Cuaresma, Balázs Égert and Ronald MacDonald, Non-Linear Exchange Rate Dynamics in Target Zones: A Bumpy Road towards a Honeymoon - Some Evidence from the ERM, ERM2 and Selected New EU Member States, July 2005

1512 David S. Evans and Michael Salinger, Curing Sinus Headaches and Tying Law: An Empirical Analysis of Bundling Decongestants and Pain Relievers, August 2005

1513 Christian Keuschnigg and Martin D. Dietz, A Growth Oriented Dual Income Tax, July 2005

1514 Fahad Khalil, David Martimort and Bruno Parigi, Monitoring a Common Agent: Implications for Financial Contracting, August 2005

1515 Volker Grossmann and Panu Poutvaara, Pareto-Improving Bequest Taxation, August 2005

1516 Lars P. Feld and Emmanuelle Reulier, Strategic Tax Competition in Switzerland: Evidence from a Panel of the Swiss Cantons, August 2005

1517 Kira Boerner and Silke Uebelmesser, Migration and the Welfare State: The Economic Power of the Non-Voter?, August 2005

1518 Gabriela Schütz, Heinrich W. Ursprung and Ludger Wößmann, Education Policy and Equality of Opportunity, August 2005

1519 David S. Evans and Michael A. Salinger, Curing Sinus Headaches and Tying Law: An Empirical Analysis of Bundling Decongestants and Pain Relievers, August 2005

1520 Michel Beine, Paul De Grauwe and Marianna Grimaldi, The Impact of FX Central Bank Intervention in a Noise Trading Framework, August 2005

1521 Volker Meier and Matthias Wrede, Pension, Fertility, and Education, August 2005

1522 Saku Aura and Thomas Davidoff, Optimal Commodity Taxation when Land and Structures must be Taxed at the Same Rate, August 2005

1523 Andreas Haufler and Søren Bo Nielsen, Merger Policy to Promote 'Global Players'? A Simple Model, August 2005

1524 Frederick van der Ploeg, The Making of Cultural Policy: A European Perspective, August 2005

1525 Alexander Kemnitz, Can Immigrant Employment Alleviate the Demographic Burden? The Role of Union Centralization, August 2005

1526 Baoline Chen and Peter A. Zadrozny, Estimated U.S. Manufacturing Production Capital and Technology Based on an Estimated Dynamic Economic Model, August 2005

1527 Marcel Gérard, Multijurisdictional Firms and Governments' Strategies under Alternative Tax Designs, August 2005 